\title{
RESULTADOS DE MONITORAMENTO E AVALIAÇÃO DOS PROGRAMAS ESPORTE E LAZER DA CIDADE (PELC) E VIDA SAUDÁVEL (VS) ${ }^{1}$
}

Recebido em: $12 / 03 / 2017$

Aceito em: 25/10/2018

\author{
Márcia Miranda Soares ${ }^{2}$ \\ Aline Souza Guadanini ${ }^{3}$ \\ Universidade Federal de Minas Gerais \\ Belo Horizonte - MG - Brasil
}

\begin{abstract}
RESUMO: O artigo apresenta os resultados de monitoramento e avaliação dos programas PELC e VS no período de 2013 a 2015, obtidos a partir do Sistema de Monitoramento e Avaliação Mimboé. Os achados apontam que os objetivos dos programas foram em grande parte alcançados, tendo destaque: a oferta de atividades sistemáticas (oficinas) e assistemáticas (eventos) em núcleos de esporte e lazer nos municípios, de forma diversificada, participativa e dialogando com a cultura local. Também foram capacitados mais de 16 mil agentes sociais em formações presenciais. Dentre os desafios, se apresentam: instabilidade dos programas, exemplar disso é nenhum convênio ter sido firmado em 2016; concentração de convênios no Sudeste e em municípios com melhores condições socioeconômicas; necessidade de aperfeiçoamentos em aspectos da implementação, como: grade-horária, entidade de controle social, conselho gestor e municipalização dos programas.
\end{abstract}

PALAVRAS CHAVE: Monitoramento. Esportes. Atividades de Lazer.

\section{RESULTS OF MONITORING AND EVALUATION OF THE ESPORTE E LAZER DA CIDADE (PELC) AND VIDA SAUDÁVEL (VS) PROGRAMS}

ABSTRACT: The article presents the results of monitoring and evaluation of the PELC and VS programs in the period from 2013 to 2015, obtained from the Mimboé Monitoring and Evaluation System. The findings indicate that the objectives of the programs were largely achieved, with emphasis on the provision of systematic (workshops) and unsystematic (events) activities in sports and leisure centers in the municipalities, in a diversified and participatory manner and in dialogue with the local culture. Also, more than 16 thousand social agents were qualified in face-to-face

\footnotetext{
${ }^{1}$ Este artigo é resultado de trabalho desenvolvido a partir de parceria da Universidade Federal de Minas Gerais com o Ministério do Esporte para o monitoramento e avaliação dos referidos programas.

2 Doutora em Ciência Política pelo Instituto Universitário de Pesquisas do Rio de Janeiro (Iuperj), professora associada do Departamento de Ciência Política da Universidade Federal de Minas Gerais (UFMG) e pesquisadora do Núcleo de Estudos em Gestão e Política Públicas - Publicus/UFMG. Atua como consultora de monitoramento e avaliação dos programas PELC e Vida Saudável.

${ }^{3}$ Bacharel em Gestão Pública pela Universidade Federal de Minas Gerais. Atuou como estagiária e pesquisadora no monitoramento e avaliação dos programas PELC e Vida Saudável, em 2017 e 2018.
} 
training. Among the challenges are: instability of programs, an example of this is no agreement signed in 2016; concentration of agreements in the Southeast region and in municipalities with better socioeconomic conditions; need for improvements in aspects of implementation, such as: hourly grading, social control entity, management council and municipalization of programs.

KEYWORDS: Monitoring. Sports. Leisure Activities.

\section{Introdução}

A política de esporte e lazer se fortaleceu no âmbito do governo nacional com a criação do Ministério do Esporte, em 2003. Esse órgão foi estruturado em três secretárias que buscaram refletir a diversidade de aspectos relacionados ao esporte, como prática social e política pública: Secretaria Nacional de Esporte Educacional (Sneed); Secretaria Nacional de Desenvolvimento do Esporte e do Lazer (Sndel) e Secretaria Nacional de Esporte de Alto Rendimento (Snear).

O Programa Esporte e Lazer da Cidade (PELC) surgiu também em 2003, na Sndel, e, em 2011, passaria a integrar a nova Secretaria Nacional de Esporte, Educação, Lazer e Inclusão Social (Snelis). Em seu desenvolvimento, o programa buscou adequar a oferta de serviços de esporte e lazer a características da população, o que acabou por diferenciar duas faixas etárias de público: os adultos, acima de 45 anos, e os idosos, a partir de 60 anos, o que levou a configuração da modalidade PELC Vida Saudável para este último público. Em 2012, essa modalidade acabou por configurar-se como um programa independente, o programa Vida Saudável (VS).

Os programas sociais PELC e VS têm como objetivo geral compartilhado “democratizar o lazer e o esporte recreativo" a partir de três iniciativas fundamentais: 1) Implementação e desenvolvimento de núcleos de esporte recreativo e de lazer para oferta de atividades contínuas (sistemáticas) e temporárias (assistemáticas); 2) 
Formação continuada de agentes envolvidos com a política de lazer e esporte; e 3) Monitoramento e avaliação da política. (BRASIL, 2016a; BRASIL, 2016b). A implementação dos programas é feita a partir de parcerias estabelecidas entre o Ministério do Esporte e governos municipais, estaduais, universidades e institutos de ensino, prevalecendo os convênios celebrados com municípios.

O monitoramento e a avaliação sempre estiveram no desenho desses programas, mas a definição e implementação de tais práticas sofreram alterações e descontinuidades ao longo do tempo. A partir de 2013 tem-se um processo continuado de atuação neste eixo, o que resultou na conformação do Sistema de Monitoramento e Avaliação dos Programas PELC e VS, denominado Mimboé ${ }^{4}$, que se encontra na atualidade em pleno funcionamento. Construído de forma participativa, o Mimboé apresenta indicadores de resultados, associados aos objetivos geral e específicos dos programas, instrumentos de coletas de dados para obtenção destes indicadores, fluxo de informações, sistemática de alimentação, de processamento e de divulgação dos resultados.

Desenvolvido em plataforma web, o Mimboé é um sistema online que utiliza a tecnologia para garantir maior segurança, acessibilidade, processamento e uso das informações produzidas. O sistema possibilita informações perenes e em tempo real sobre o andamento dos dois programas e também informações agregadas sobre a situação de todos os convênios em relação aos seus indicadores, a partir da ferramenta "Extrator de Indicadores". Essa ferramenta possibilita a produção de relatórios anuais de monitoramento e avaliação, que também faz uso de outras informações de convênios do Ministério do Esporte, assim como de dados secundários do Instituto Brasileiro de

\footnotetext{
${ }^{4}$ Palavra que tem origem na língua Tupi-Guarani e que significa "o ensinado".
} 
Geografia e Estatística (IBGE) e do Programa das Nações Unidas para o Desenvolvimento (PNUD).

O presente artigo apresenta os resultados do segundo e mais recente relatório de monitoramento e avaliação dos programas PELC e VS, que tem como base 76 convênios celebrados com 74 municípios, vigentes no período de 2013 a $2015^{5}$. Os anos mais recentes não foram considerados porque não houve conveniamento em 2016 e os de 2017 estão em fase de implantação, com poucos dados no Mimboé (SOARES; GUADANINI, 2018).

Para exposição e análise dos resultados, o artigo está organizado em três seções, além dessa Introdução e das Conclusões. A primeira seção apresenta uma descrição quantitativa dos programas nos municípios, destacando o número de convênios por ano, por região, por porte populacional dos municípios e por tipo de programa. Também apresenta e analisa o perfil socioeconômico médio dos municípios que implantaram o PELC e VS, a partir de três indicadores: PIB per capita, Índice de Desenvolvimento Humano Municipal (IDHM) e Índice de Gini. O objetivo é comparar os municípios contemplados pelos programas com o conjunto dos municípios brasileiros, com vistas a identificar divergências e semelhanças entre os dois grupos. Esses dados foram extraídos do IBGE (2016; 2017a) e do Atlas do Desenvolvimento Humano no Brasil, do PNUD (2013).

A segunda seção apresenta a situação da política de esporte em municípios que são beneficiários do PELC e VS, comparando-os com o conjunto dos municípios brasileiros a partir de três dimensões: órgão gestor e legislação do esporte; conselho

\footnotetext{
${ }^{5}$ Foram desconsiderados os convênios finalizados (expirados e cancelados) e os 7 convênios firmados com universidades ou órgãos do governo estadual. Isso porque estes convênios seguem uma lógica distinta da grande maioria, que tem como base o município.
} 
municipal de esporte; e ações e programas de esporte. As informações são do Anexo Esporte da Pesquisa de Informações Básicas Municipais 2016 (IBGE, 2017b)

A terceira seção apresenta e analisa os resultados de monitoramento e avaliação a partir dos indicadores estabelecidos para captar o alcance dos objetivos dos programas a partir do "Extrator de Indicadores" do Mimboé, ferramenta que organiza em planilha de Excel informações selecionadas dos instrumentos alimentados no Sistema.

Nas Conclusões são sintetizados os principais resultados encontrados, os mais satisfatórios e aqueles que apresentam desafios para os programas. Com isso, têm-se uma agenda para tomada de decisões na busca pelo aperfeiçoamento da política de esporte e lazer do governo nacional.

\section{Perfil dos Municípios Beneficiários dos Programas PELC e VS}

Entre 2013 e 2015 foram firmados 76 convênios entre o Ministério do Esporte (ME) com municípios, sendo 10 em 2013, 26 em 2014, e 40 em 2015. Em um contexto de ajuste fiscal, os dados apontam um quadro bastante irregular de conveniamento, o que foi exacerbado pelo ano de 2016, quando não houve qualquer convênio firmado. A grande maioria dos convênios é do programa PELC, 62 convênios $(81,6 \%)$, sendo 14 os convênios do programa Vida Saudável (18,4\%).

Em relação à distribuição dos convênios por região, tem-se 41 (54\%) no Sudeste, 19 (25\%) no Nordeste, 7 (9\%) no Sul, 5 (7\%) no Norte e 4 (5\%) no Centro Oeste, o que denota um quadro bastante desigual na distribuição regional dos programas, com grande concentração no Sudeste.

A Figura 1 apresenta os municípios beneficiários do PELC e VS por porte populacional, conforme a projeção para o ano de 2015 (IBGE, 2017a). É possível 
verificar que $11(14 \%)$ municípios apresentavam população acima de 500 mil habitantes; 22 (29\%) municípios encontravam-se no corte populacional de 100.001 a 500.000 habitantes; e 18 (24\%) estavam na faixa entre 50.001 e 100 mil. Abaixo de 50 mil habitantes, considerados de pequeno porte, havia 25 municípios (33\%). É uma realidade distinta da brasileira que apresenta: $303(5,44 \%)$ dos municípios no corte populacional de 100.001 a 500.000 habitantes e $4.916(88,25 \%)$ municípios abaixo de 50 mil habitantes. Com isso, tem-se a prevalência de municípios de médio porte dentre os beneficiários do PELC e VS, enquanto a realidade brasileira é de municípios de pequeno porte (abaixo de 50 mil habitantes).

Figura 1: quantidade de convênios PELC e VS, por porte populacional

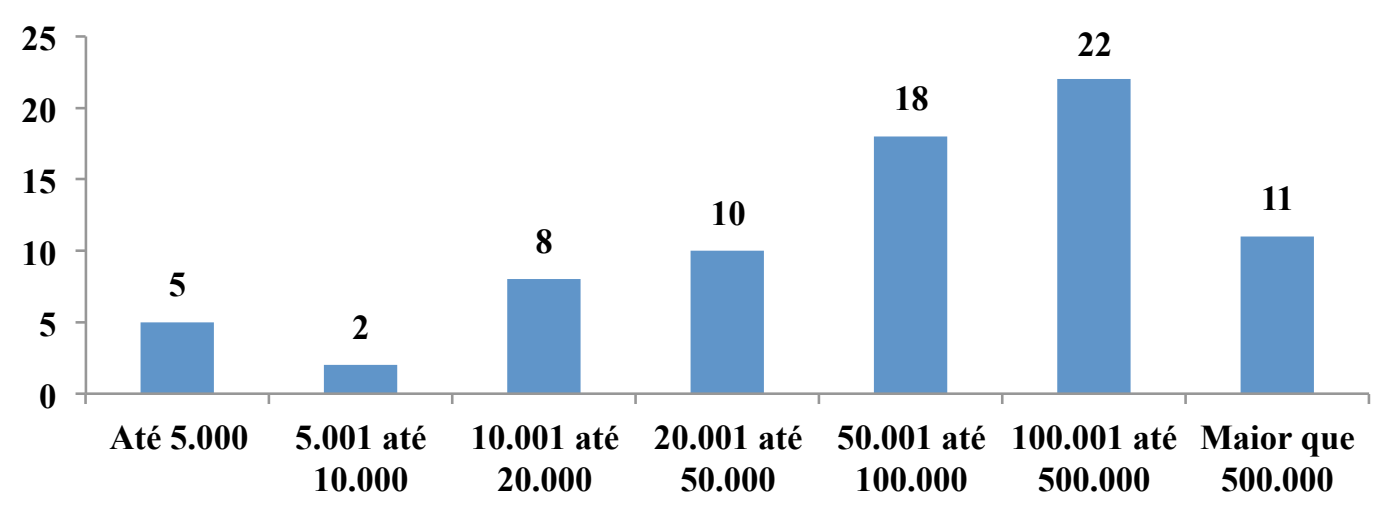

Fontes: IBGE, 2017a. Nota: São 76 convênios com 74 municípios (BRASIL, 2018a).

Em relação às características socioeconômicas, foram utilizadas informações de PIB per capita ${ }^{6}$, IDHM $^{7}$ e Índice de Gini ${ }^{8}$, comparando a média destes indicadores para os beneficiários dos programas com a média dos municípios brasileiros. Na Tabela 1

\footnotetext{
${ }^{6}$ O PIB per capita é a razão entre a riqueza e o número de habitantes de uma determinada região.

${ }^{7}$ O Índice de Desenvolvimento Humano Municipal (IDHM) é um indicador adaptado do IDH, desenvolvido pela Organização das Nações Unidas (ONU) para atender aos municípios brasileiros. Ele é construído a partir de três dimensões: expectativa de vida, educação e PIB per capita.

${ }^{8} \mathrm{O}$ Índice ou Coeficiente de Gini é utilizado para medir a desigualdade de distribuição de renda e varia de zero a um, quanto mais próximo de 0 , menor a desigualdade na distribuição de renda, e quanto mais próximo de 1 , maior a desigualdade na distribuição de renda.
} 
observa-se que os municípios PELC e VS apresentam PIB per capita melhor que a média nacional, a exceção do Centro-Oeste, que só tem 4 municípios conveniados. Também no IDHM, a média é maior para os municípios que aderiram aos programas e isso ocorre para todas as regiões. Diversamente, o Índice de Gini é o único indicador que apresenta uma situação melhor para a média dos municípios brasileiros, ou seja, os municípios beneficiários, em média, são mais desiguais que os municípios brasileiros.

Tabela 1: perfil socioeconômico dos municípios brasileiros e do PELC e VS, por região

\begin{tabular}{|c|c|c|c|c|c|c|}
\hline Região & $\begin{array}{c}\text { PIB per capita } \\
\text { PELC e VS } \\
(2014)^{1 / 2}\end{array}$ & $\begin{array}{l}\text { PIB per capita } \\
\text { Brasil }(2014)^{1 / 2}\end{array}$ & $\begin{array}{c}\text { IDHM } \\
\text { PELC e VS } \\
(2010)^{3}\end{array}$ & $\begin{array}{c}\text { IDHM Bra } \\
(2010)^{3}\end{array}$ & $\begin{array}{l}\text { IIGini PELC } \\
\text { e VS } \\
(2010)^{3}\end{array}$ & $\begin{array}{l}\text { Gini Brasi } \\
(2010)^{3}\end{array}$ \\
\hline$\overline{\mathrm{Sul}}$ & $29.314,61$ & $26.976,11$ & 0,744 & 0,714 & 0,48 & 0,46 \\
\hline $\begin{array}{l}\text { Centro- } \\
\text { Oeste }\end{array}$ & $25.726,82$ & $26.251,99$ & 0,772 & 0,698 & 0,55 & 0,50 \\
\hline Sudeste & $27.068,62$ & $22.389,53$ & 0,733 & 0,699 & 0,48 & 0,47 \\
\hline Norte & $13.908,32$ & $12.898,78$ & 0,674 & 0,608 & 0,58 & 0,57 \\
\hline Nordeste & $13.540,77$ & $9.102,81$ & 0,652 & 0,591 & 0,55 & 0,53 \\
\hline Brasil & $22.889,49$ & $18.647,91$ & 0,711 & 0,659 & 0,51 & 0,49 \\
\hline
\end{tabular}

Fontes: 1. IBGE, 2016; 2. IBGE, 2017a; 3. PNUD, 2013. Nota: São 76 convênios com 74 municípios (BRASIL, 2018a).

\section{A Situação do Esporte nos Municípios Beneficiários dos Programas PELC e VS}

A partir do Suplemento Especial de Esporte da Pesquisa de Informações Básicas Municipais (Munic), realizada em 2016 e publicada em 2017 (IBGE, 2017b), pode-se comparar a situação da política de esporte nos municípios beneficiários dos PELC e Vida Saudável com a vigente no total dos municípios brasileiros. Este Suplemento contém diversas informações sobre os a política municipal de esportes, sendo que o presente artigo destaca os seguintes aspectos: órgão gestor; legislação; conselho municipal de esporte; e ações e programas de esporte. 
Em relação ao órgão gestor de esporte nos municípios, observa-se na Figura 2 que $23 \%$ dos municípios conveniados possuem secretaria exclusiva de esporte, contra $12 \%$ do conjunto de municípios brasileiros. Nos dois grupos prevalece secretaria municipal em conjunto com outra política: $64 \%$ para os municípios PELC e VS e $63 \%$ para o conjunto dos municípios brasileiros. Aonde há este agrupamento, o esporte geralmente compartilha secretaria com o lazer, o que mostra a afinidade entre essas duas políticas públicas. Tal situação é ligeiramente mais presente nos munícipios PELC e VS (47\%) que nos municípios brasileiros (43\%). Somente 2\% de municípios brasileiros não possuem nenhuma estrutura de esporte, não existindo essa situação para os municípios PELC e VS.

Figura 2: caracterização do órgão gestor do município

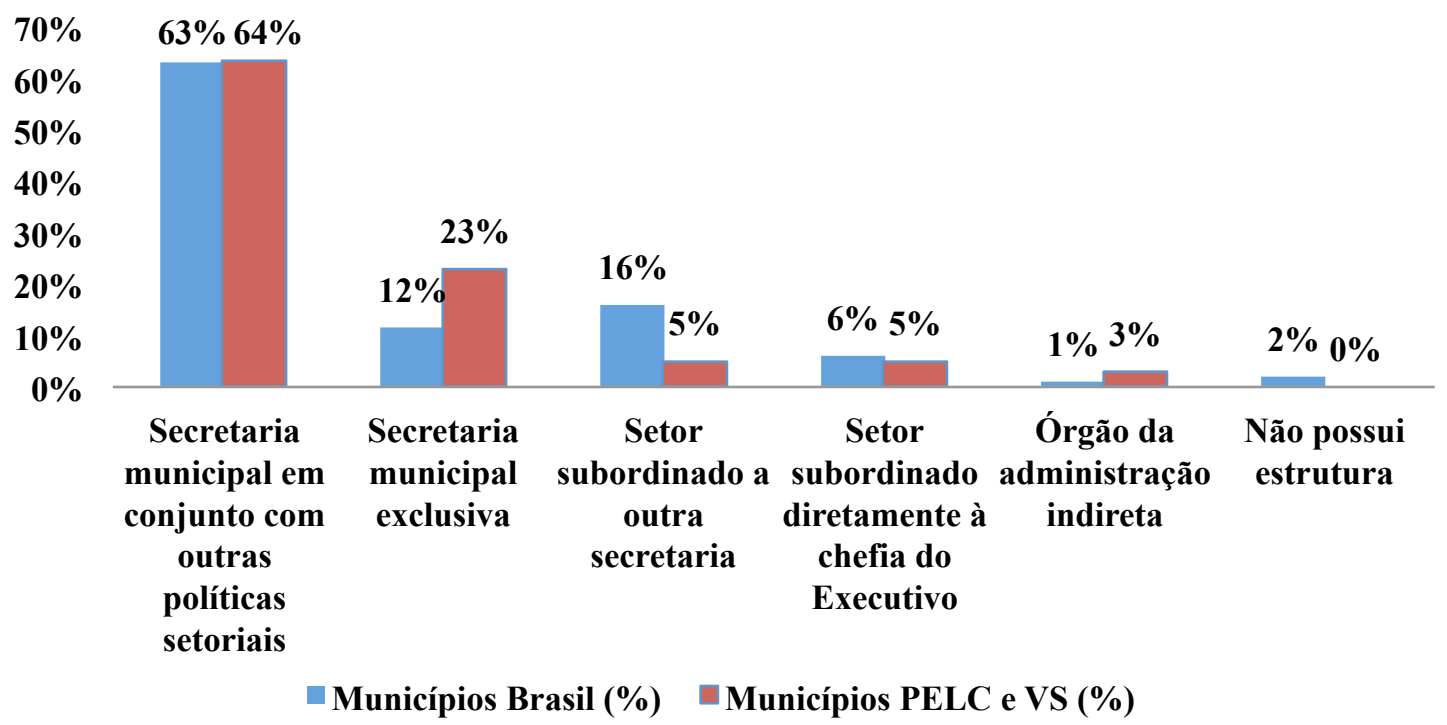

Fonte: IBGE, 2017b. Nota: Valores referentes a 5569 municípios, do total de 5570 municípios brasileiros, e 74 municípios PELC e VS (BRASIL, 2018a).

Sobre a legislação, perguntados aos municípios se a Lei Orgânica tratava do esporte, $80 \%$ dos municípios PELC e VS e $78 \%$ de todos os municípios brasileiros responderam de forma afirmativa. 
No aspecto da participação social institucionalizada, conforme Figura 3, é pequeno o número de municípios brasileiros com Conselho Municipal de Esporte (CME), apenas $21 \%$. Situação um pouco melhor ocorre para a média dos municípios PELC e VS, onde 34\% têm CME. Como são poucos os municípios que possuem CME, as maiorias das questões referentes ao CME tiveram como resposta a alternativa "Não aplicável", dificultando a análise da organização e funcionamento dos mesmos.

Figura 3: Conselho Municipal de Esporte (CME)

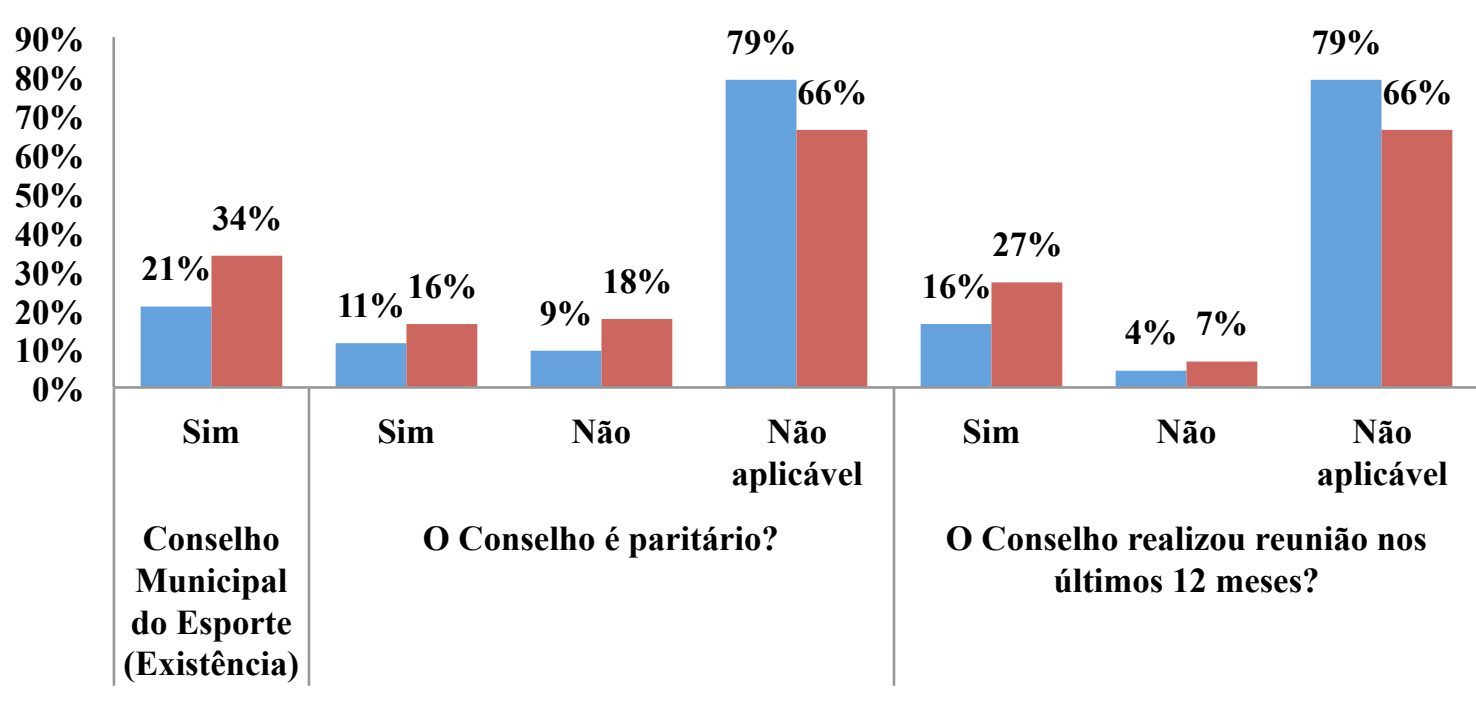

Municípios Brasil Municípios PELC e VS

Fonte: IBGE, 2017b. Nota: Valores referentes a 5.567 municípios (questão sobre a existência do CME); 5566 (questão sobre o CME ser paritário); 5.559 (questão sobre reuniões realizadas pelo CME); e 74 municípios PELC e VS (BRASIL, 2018a).

A Figura 4, sobre a execução pela prefeitura de ações, projetos ou programas de esporte, aponta que o conjunto de atividades municipais está voltado predominantemente para o esporte de lazer e para o esporte escolar: $83 \%$ dos municípios brasileiros informaram atuar no esporte escolar $^{9}$ e $88 \%$ atuar no esporte de lazer, números que se elevam para $88 \%$ e $97 \%$, respectivamente, quando se tratam dos

9 Conforme a Munic 2016, "esporte escolar é aquele praticado nos sistemas de ensino e em formas assistemáticas de educação". 
municípios PELC e VS. O esporte de rendimento é menor nos dois grupos: 62\% para os municípios do Brasil e $68 \%$ nos municípios conveniados.

Figura 4: ações, projetos e/ou programas de esporte executados pela prefeitura

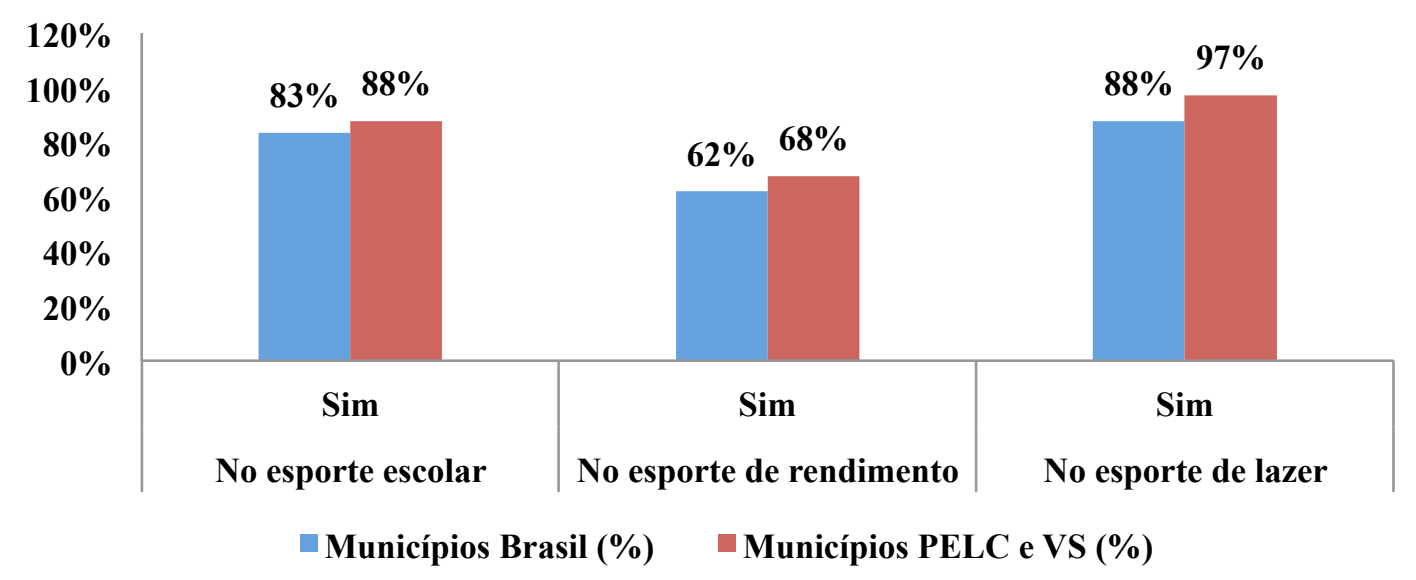

Fonte: IBGE, 2017b. Nota: Valores referentes a 5567 municípios brasileiros e; 74 municípios PELC e VS (BRASIL, 2018a).

\section{Resultados do PELC e VS a partir dos Indicadores de Monitoramento e Avaliação (2013-2015)}

Os dados para monitoramento e avaliação dos programas foram extraídos do Sistema Mimboé, em fevereiro de 2018, por meio da ferramenta Extrator de Indicadores (BRASIL, 2018b). Dois instrumentos principais de coletas de dados foram utilizados para obter informações dos programas nos municípios, o Planejamento Pedagógico (PP) e o Relatório de Visita Pedagógica (RVP). O PP é um instrumento de planejamento preenchido pelos representantes dos municípios antes da implantação do programa, ou seja, seus dados refletem a pretensão dos entes que desejam implementar os programas, aquilo que eles pretendem realizar. O RVP é instrumento de monitoramento e avaliação dos programas, preenchido por representantes da UFMG/ME em visitas de campo realizadas nos municípios quando os programas já estão sendo executados. Ele busca captar a situação de implementação dos programas, a partir dos indicadores de resultados. 
Nas subseções que seguem serão tratadas as informações obtidas sobre os vinte e cinco (25) indicadores que medem os sete (7) objetivos específicos dos programas PELC e VS. Combinados, os objetivos possibilitariam atingir o objeto geral dos programas: "democratizar o lazer e o esperte recreativo" (BRASIL, 2016a; BRASIL, 2016b). A Tabela 2 abaixo apresenta estes objetivos e seus indicadores, estando em negrito alguns poucos indicadores que ainda não puderam ser captados. No objetivo 1 não foi possível captar os dois primeiros indicadores sobre perfil dos beneficiários inscritos e participantes das atividades sistemáticas: "Inscrição nas atividades sistemáticas" e "Participação nas atividades sistemáticas". A razão é a indisponibilidade ou precariedades dessas informações na maioria dos municípios visitados. Para solucionar esse problema foi criada a aba "Beneficiários" no Mimboé, que está sendo preenchida pelos convenentes e gerará informações para esses indicadores futuramente. A mesma dificuldade de obtenção de dados em visitas aos municípios foi observada para os indicadores 2 e 3 do objetivo 3: "Aumento de recurso financeiro para lazer e esporte recreativo no município" e "Contratação de recursos humanos na área de lazer e esporte recreativo".

Tabela 2: objetivos específicos e indicadores de monitoramento e avaliação PELC e VS

\begin{tabular}{l|l}
\hline \multicolumn{1}{c|}{ Objetivos específicos } & \multicolumn{1}{c}{ Indicadores } \\
\hline \multirow{2}{*}{$\begin{array}{l}\text { 1. PELC: Nortear ações voltadas para } \\
\text { públicos diferenciados (faixa etária, } \\
\text { gênero, raça, etnia, e orientação sexual, } \\
\text { pessoas com deficiência, entre outros) } \\
\text { nos núcleos de lazer e esporte }\end{array}$} & $\begin{array}{l}\text { 1) Perfil dos beneficiários inscritos nas atividades } \\
\text { sistemáticas }\end{array}$ \\
\cline { 2 - 2 } $\begin{array}{l}\text { 2) Perfil dos beneficiários que participam das atividades } \\
\text { sistemáticas }\end{array}$ & $\begin{array}{l}\text { 3) Diversidade das atividades sistemáticas (oficinas) na } \\
\text { grade horária }\end{array}$ \\
\cline { 2 - 2 } $\begin{array}{l}\text { 1. VS. Nortear ações voltadas para } \\
\text { pessoas, predominantemente, a partir de } \\
\text { 60 anos nos núcleos de esporte e lazer. }\end{array}$ & 4) Diversidade dos espaços de inscrição \\
\cline { 2 - 2 } & 5) Diversidade das atividades assistemáticas (eventos) \\
\cline { 2 - 2 } & 6) Intergeracionalidade \\
\hline \multirow{2}{*}{ 2. Estimular a gestão participativa entre } & 1) Diversidade das entidades parceiras \\
\hline
\end{tabular}




\begin{tabular}{|c|c|}
\hline \multirow{5}{*}{$\begin{array}{l}\text { os atores locais direta e indiretamente } \\
\text { envolvidos }\end{array}$} & 2) Criação do Conselho Gestor \\
\hline & 3) Funcionamento do Conselho Gestor \\
\hline & 4) Atuação da entidade de controle social \\
\hline & 5) Metodologia participativa de construção dos eventos. \\
\hline & $\begin{array}{l}\text { 6) Grupos de comunidade, convivência, culturais e } \\
\text { esportivos formados. }\end{array}$ \\
\hline \multirow{5}{*}{$\begin{array}{l}\text { 3. Estimular a implementação de } \\
\text { metodologia participativa e democrática } \\
\text { para o desenvolvimento de políticas } \\
\text { públicas intersetoriais de lazer e esporte } \\
\text { recreativo }\end{array}$} & 1) Órgão público responsável pelo lazer e esporte. \\
\hline & $\begin{array}{l}\text { 2) Aumento de recurso financeiro para lazer e esporte } \\
\text { recreativo no município }\end{array}$ \\
\hline & $\begin{array}{l}\text { 3) Contratação de recursos humanos na área de lazer e } \\
\text { esporte recreativo. }\end{array}$ \\
\hline & $\begin{array}{l}\text { 4) Participação dos envolvidos nos processos de formação e } \\
\text { nas visitas }\end{array}$ \\
\hline & 5) Perspectivas de continuação do programa. \\
\hline \multirow{2}{*}{$\begin{array}{l}\text { 4. Promover a formação inicial e } \\
\text { estimular a formação continuada dos } \\
\text { agentes sociais e gestores municipais de } \\
\text { lazer e esporte recreativo }\end{array}$} & 1) Agentes sociais e gestores municipais diversos formados \\
\hline & 2) Formação em serviço realizada com qualidade \\
\hline \multirow{3}{*}{$\begin{array}{l}\text { 5. Valorizar e fortalecer a cultura local } \\
\text { na apropriação do direito ao lazer e ao } \\
\text { esporte recreativo }\end{array}$} & $\begin{array}{l}\text { 1) Contribuição do PELC para as festividades tradicionais } \\
\text { organizadas pela comunidade local. }\end{array}$ \\
\hline & 2) Formação de grupos culturais a partir do PELC \\
\hline & $\begin{array}{l}\text { 3) Utilização de aspectos da cultura local na organização } \\
\text { das atividades sistemáticas (oficinas) e atividades } \\
\text { assistemáticas (eventos). }\end{array}$ \\
\hline \multirow{2}{*}{$\begin{array}{l}\text { 6. Promover a ressignificação e a } \\
\text { qualificação de espaços e equipamentos } \\
\text { públicos de lazer e esporte recreativo }\end{array}$} & 1) Mudança no uso de espaços públicos \\
\hline & $\begin{array}{l}\text { 2) Construção ou reforma dos equipamentos para uso do } \\
\text { PELC }\end{array}$ \\
\hline $\begin{array}{l}\text { 7. Democratizar o acesso ao lazer e } \\
\text { esporte recreativo, privilegiando as } \\
\text { comunidades menos favorecidas }\end{array}$ & 1) Acesso das comunidades menos favorecidas ao Programa \\
\hline
\end{tabular}

Fonte: BRASIL, 2014.

\section{Nortear ações voltadas para públicos diferenciados}

A fim de verificar se as ações desenvolvidas nos núcleos estão voltadas para públicos variados, buscou-se captar informações sobre a diversidade das atividades sistemáticas (oficinas) oferecidas, por meio da grade-horária formulada pelos municípios, a diversidade dos espaços de inscrição, a diversidade das atividades assistemáticas (eventos) e a intergeracionalidade das ações. 
Sobre a grade horária das atividades sistemáticas, para 21 convênios com informações no $\mathrm{RVP}^{10}$, observou-se que a grade estava sendo cumprida plenamente em 11, parcialmente em 7; e não estava sendo cumprida em 3. Ainda, em 20 convênios elas foram modificadas e em 11 convênios ela não estava em local visível e era diferente daquela que constava no Mimboé. Ainda em relação às atividades sistemáticas, estas foram consideradas diversificadas (81\%) e adequadas ao público-alvo (95\%).

Em relação às atividades assistemáticas (eventos), de 20 convênios com respostas no RVP, $85 \%$ afirmaram executá-las mensalmente e $71 \%$, agora em um total de 21 respondentes, que a metodologia de planejamento das atividades assistemáticas era participativa.

Dos 65 convênios com informações no PP, e podendo assinalar mais de uma alternativa, 55 deles manifestaram que iriam realizar as inscrições dos participantes nas oficinas nos locais onde iriam funcionar os núcleos e subnúcleos; 49 na sede da entidade proponente (Prefeitura), 23 em centros comunitários, 21 em sedes das entidades parceiras e apenas 5 optaram por utilizar a internet.

Considerando o caráter intergeracional dos programas, é importante que sejam previstas atividades sistemáticas e assistemáticas que favoreçam e estimulem o convívio entre gerações. Em 19 dos 21 convênios com informações disponíveis no RVP, as atividades sistemáticas realizadas contemplavam alguma ação intergeracional.

${ }^{10}$ O RVP é o principal instrumento de monitoramento e avaliação e ele é preenchido em fase mais avançada de execução do programa, a partir de visita pedagógica aos municípios. As visitas são realizadas no mínimo uma vez durante a execução de cada convênio. Assim, apesar de 76 convênios vigentes no período de análise, somente em torno de um terço deles tiveram as visitas e, portanto, apresentam dados para muito dos indicadores. Também nem sempre há o preenchimento de todas as questões. 


\section{Estimular a gestão participativa entre os atores locais direta e indiretamente envolvidos com os programas}

Para captar se os programas tiveram êxito em estimular a gestão participativa entre os atores locais foram levados em conta os seguintes fatores: diversidade das entidades parceiras ${ }^{11}$, a criação e funcionamento do conselho gestor ${ }^{12} \mathrm{e}$ a atuação da entidade de controle social ${ }^{13}$.

Conforme dados de 15 convênios no RVP, as principais entidades parceiras são instituições públicas (82\%), organizações não-governamentais - ONGs (59\%), empresas privadas $(24 \%)$ e outras (24\%). Essas entidades contribuem, principalmente, com a disponibilização de infraestrutura (60\%) para as atividades dos programas. Com base em informações de 17 convênios, em média, cada convênio possui quatro (4) entidades parceiras.

O conselho gestor foi criado em 13 dos 21 convênios com informações disponíveis no RVP. Dentre os criados, $46 \%$ se reúnem mensalmente; $31 \%$ bimestralmente; $8 \%$ trimestralmente; e 15\% reúnem-se em outra periodicidade. Quanto à sua composição, para 12 convênios com informações, tem-se a representação: da entidade convenente $(100 \%)$; das entidades parceiras $(91 \%)$; do coordenador dos programas (91\%); de agentes sociais $(83 \%)$ e da entidade de controle social $(66 \%)$.

Dos 20 convênios com informações disponíveis, 65\% disseram que os representantes da entidade de controle Social não acompanhavam as atividades sistemáticas. Quanto às atividades assistemáticas, dos 21 convênios com informações,

\footnotetext{
${ }^{11}$ As entidades parceiras são instituições municipais que auxiliam na implementação do convênio.

${ }^{12} \mathrm{O}$ conselho gestor é uma instância a ser estruturada no âmbito dos programas com funções consultivas, deliberativas e executivas, composta por representantes dos diversos segmentos envolvidos no desenvolvimento das ações dos núcleos de Esporte e Lazer. O grupo gestor tem ainda o compromisso de acompanhar, fiscalizar e monitorar as ações do convênio, buscando superar as dificuldades, e melhor qualificar a execução dos programas. (BRASIL, 2016a)

${ }^{13}$ A entidade de controle social tem como função fiscalizar a execução do convênio e acompanhar as atividades desenvolvidas pelo projeto local, durante o processo de conveniamento. (BRASIL, 2016a)
} 
$52 \%$ disseram que não havia acompanhamento das mesmas. Isso aponta baixa participação destas entidades no desenvolvimento das atividades dos programas.

Em relação ao indicador sobre a utilização de metodologia participativa de construção dos eventos, conforme já apontando acima, $71 \%$, em um total de 21 respondentes, afirmaram ser participativo o processo de definição e realização dos eventos.

\section{Estimular a implementação de metodologia participativa e democrática para o desenvolvimento de políticas públicas intersetoriais de lazer e esporte recreativo}

Este objetivo está relacionado ao fortalecimento das políticas de esporte e lazer nos municípios a partir adoção dos programas PELC e VS. Espera-se que esses programas possam estimular o fortalecimento do órgão público responsável por lazer e esporte, a ampliação de recursos financeiros e humanos para essas políticas, a qualificação dos gestores públicos de esporte e lazer e a continuidade dos programas para além do convênio celebrado pelo Ministério do Esporte (municipalização da política).

Em relação ao setor responsável pelo esporte e lazer nos municípios, estes foram caracterizado na seção acima, a partir das informações da Munic 2016 (IBGE, 2017b). No aspecto da municipalização dos programas, ou seja, sua continuidade após o encerramento da parceria com o ME, a partir de respostas dos gestores municipais no PP, em 51 convênios com informações, 22 (43\%) disseram que irão continuar com os programas PELC e VS após a finalização do convênio e 29 (57\%) não souberam responder. Em relação às estratégias para continuar com o programa, com base em 61 convênios com informações: $46(75,4 \%)$ apontaram que buscarão realizar novo convênio com o ME; 35 (57,4\%) que buscarão novas fontes de recursos; 25 (41\%) que 
irão aumentar os aportes de recursos financeiras próprios nos programas; e 9 (14,8\%) disseram que irão recorrer a outros recursos.

A mesma informação foi coletada no RVP, ou seja, com os programas plenamente em funcionamento. Neste caso, dos 21 convênios com informações, $71 \%$ afirmaram que buscarão estratégias para dar continuidade aos programas e, para isso, a principal estratégica é realizar novo convênio com o ME (38\%), seguida por buscar novas fontes de recursos (19\%) e aumentar o aporte de recursos financeiros (13\%).

Ainda, em 17 convênios com informações no RVP, 9 (53\%) acreditam que o período de vigência do convênio, 24 meses, é insuficiente para garantir a continuidade dos programas após o fim do convênio. Tanto no PP quanto no RVP observa-se que a principal estratégia para continuidade dos programas é novo convênio com o ME.

\section{Promover a formação inicial e estimular a formação continuada dos agentes sociais e gestores municipais de lazer e esporte recreativo ${ }^{14}$}

A fim de medir o alcance desse objetivo, foram captadas informações sobre dois indicadores: "Agentes sociais e gestores municipais diversos formados" e "Formação em serviço ${ }^{15}$ realizada com qualidade". Um dos eixos principais dos programas PELC e Vida Saudável são a formação presencial de agentes sociais de esporte e lazer realizada pela UFMG. A formação é feita a partir de módulos com conteúdos específicos, sendo que até o ano de 2013 havia três módulos, um introdutório e dois de avaliação; a partir de 2014, a formação adquiriu a configuração que vigora até a atualidade, com quatro

\footnotetext{
${ }^{14}$ Os indicadores desse objetivo contemplam também o indicador do objetivo 3 (3.4).

${ }^{15}$ A formação em serviço é realizada por meio de reuniões semanais que servem para estudo, troca de ideias, planejamento, palestras e oficinas, em cada um dos núcleos com organização, financiamento e realização sob responsabilidade da entidade conveniada. Participam das formações os coordenadores pedagógicos setoriais (quando houver), coordenadores de núcleos e agentes sociais. (BRASIL, 2016a)
} 
módulos: Módulo Introdutório I, Módulo Introdutório II, Módulo de Avaliação I e Módulo de Avaliação II.

A partir de 2016, a UFMG, em parceria com o ME, passou a ofertar também módulos de formação à distância, fomentando a efetivação da formação continuada de agentes socais de esporte de lazer. Os módulos dos cursos ofertados de EaD podem ser acessados por um público variado, interessado nas discussões do esporte e lazer, de forma gratuita e com possibilidade de certificação.

Conforme Tabela 3, foram realizadas 416 formações no período de 2013 a 2017, sendo 304 formações no âmbito do PELC e 112 no programa Vida Saudável. No total, formou-se 16.582 agentes sociais de esporte e lazer em cinco anos.

Tabela 3: Formações realizadas, por programas e ano (2013 a 2017)

\begin{tabular}{l|c|c|c}
\hline \multirow{2}{*}{ Ano } & \multicolumn{2}{|c|}{ Número de formações } & \multirow{2}{*}{$\begin{array}{c}\text { Número de } \\
\text { participantes }\end{array}$} \\
\cline { 2 - 3 } & PELC & Vida Saudável & 1.080 \\
2013 & 35 & 10 & 2.258 \\
2014 & 35 & 23 & 3.788 \\
2015 & 77 & 44 & 4.968 \\
2016 & 73 & 21 & 4.488 \\
2017 & 84 & 14 & $\mathbf{1 6 . 5 8 2}$ \\
TOTAL & $\mathbf{3 0 4}$ & $\mathbf{1 1 2}$ & \\
\hline
\end{tabular}

Fonte: UFMG/EEFFTO, 2018.

Em relação à formação e serviço, com base em 21 convênios com informações no RVP, 19 a realizaram e 2 não. Questionados sobre como estariam sendo realizadas estas formações, podendo ser assinaladas mais de uma alternativa, obteve-se que: 18 realizaram reuniões pedagógicas da equipe de trabalho; 11 participaram de cursos, oficinas e palestras; 6 realizaram grupos de estudo para leitura e discussão dos textos; 4 cursaram ensino à distância; e 3 participaram de atividades de campo e eventos. Em relação aos participantes dessas formações, observou-se que os principais grupos foram 
os agentes sociais ${ }^{16}$ e coordenadores dos programas (geral, pedagógico, setorial e de núcleo).

\section{Valorizar e fortalecer a cultura local na apropriação do direito ao lazer e ao esporte recreativo}

O lazer e o esporte recreativo podem ser acessados como um direito do cidadão a partir de atividades diversas que não devem ser elementos estranhos à população, mas que devem dialogar com a cultura local. Para esse objetivo foram tratados os seguintes indicadores: "Contribuição do PELC para as festividades tradicionais organizadas pela comunidade local"; "Quantidade de grupos de comunidade, convivência, culturais e esportivos formados"; e "Utilização de aspectos da cultura local na organização das oficinas e eventos".

Dos 21 convênios com informações disponíveis no RVP, em 90\% dos casos, gestores, agentes sociais e beneficiários contribuíram para as festividades organizadas pela comunidade local. O mesmo percentual de $90 \%$ é observado na afirmação positiva de que a entidade convenente teve boa capacidade de organização e mobilização da comunidade. Também foi observada a atuação de lideranças comunitárias nos programas em $62 \%$ dos 21 casos com informações.

A formação de grupos culturais a partir dos programas parece ser uma situação excepcional. Em 16 convênios, de 18 com informações disponíveis no RVP, não houve a formação de nenhum grupo de comunidade, convivência, culturais e esportivos. Somente houve a formação de um (1) grupo de comunidade e de um (1) grupo artístico.

Quanto à valorização da cultura local, apontou-se diálogo com a cultura local na organização das oficinas (atividades sistemáticas) para $81 \%$ dos casos e em $65 \%$ houve

${ }^{16}$ Os agentes sociais correspondem aos professores de educação física, aos educadores populares e comunitários e a outros profissionais que atuam em áreas afins ao lazer ou que estão envolvidos diretamente com a execução do programa. 
esse diálogo na construção dos eventos (atividades assistemáticas), de 20 convênios com respostas no RVP.

\section{Promover a ressignificação e a qualificação de espaços e equipamentos públicos de lazer e esporte recreativo}

Os programas PELC e VS têm entre seus principais propósitos a disponibilização de equipamentos públicos para a prática de lazer e esporte recreativo (Núcleos de Lazer e Esporte Recreativo). Para compreender se houve ressignificação dos espaços e equipamentos públicos de lazer e esporte recreativo com esse propósito, foram formuladas as seguintes questões dirigentes aos gestores municipais da política: houve necessidade de modificar os espaços públicos já existentes ou de se criar novos espaços? Os espaços públicos disponíveis já vinham sendo utilizados pela população?

Com base nos 21 convênios com informações disponíveis no RVP, 62\% dos convenentes responderam que foi necessário modificar os espaços públicos para abrigar núcleos ou subnúcleos e 56\% disseram, em 20 respondentes, que os espaços já estavam sendo utilizados pela população. Além disso, praticamente não foram criados novos espaços para abrigar núcleo ou subnúcleos, somente $5 \%$.

\section{Democratizar o acesso ao lazer e esporte recreativo, privilegiando as comunidades menos favorecidas}

Para captar se os programas tiveram êxito em democratizar o acesso ao lazer e esporte recreativo, privilegiando as comunidades menos favorecidas, além de informações sobre os municípios tratadas na seções 1 e 2 acima, foram levados em conta os seguintes fatores: diversidade das formas de divulgação do programa; disponibilidade de banners e material para divulgação do programa nos locais visitados; e concessão de auxílio deslocamento. Futuramente, com as informações que passarão a serem coletadas dos beneficiários, outros indicadores desse objetivo poderão ser 
captados, por exemplo, a presença dos programas em bairros com população mais pobre.

Quanto às formas de divulgação do programa, dentre 55 informações disponíveis no PP, os convenentes apontaram em seu planejamento que utilizariam principalmente internet, faixas ou banners, cartazes e panfletos como formas de divulgação dos programas.

Também a partir do PP, dos 54 convênios com informações disponíveis, 49 apontaram que fariam as inscrições na sede de entidades parceiras, 48 nos locais onde funcionarão os núcleos, 41 na sede da entidade proponente e somente 4 pela internet.

Questionados sobre a oferta de auxílios aos beneficiários para participação em atividades sistemáticas e assistemáticas, conforme o RVP, apenas 1 convenente, dentre 21 convênios com informações, disseram oferecer auxílio para o deslocamento da população para as atividades sistemáticas. O auxílio em questão era ônibus gratuito. Quanto às atividades assistemáticas, dos 19 convênios com informações, 8 disseram oferecer auxílio deslocamento, prevalecendo a oferta de ônibus gratuito.

\section{Considerações Finais}

Este artigo apresentou os resultados do monitoramento e avaliação dos programas Esporte e Lazer da Cidade (PELC) e Vida Saudável (VS) do Ministério do Esporte a partir de indicadores captados e alimentados no Sistema Mimboé. Os resultados têm como base, principalmente, informações de 76 convênios celebrados com 74 municípios e vigentes no período de 2013 a 2015.

Na primeira seção foi apresentada a caracterização dos convênios PELC e VS nos municípios. Os dados mostram que os convênios PELC e VS se concentraram 
principalmente na região Sudeste $(54 \%)$ e que têm uma presença expressiva em municípios de médio e grande porte populacional, acima de 50 mil habitantes (67\%). Em relação à adesão aos programas, a maioria dos convênios é PELC (82\%).

Observou-se ainda, em relação ao perfil dos municípios que adotaram os programas PELC e VS, uma melhor situação socioeconômica que a média dos municípios brasileiros em relação ao PIB per capita e IDHM. O único aspecto socioeconômico que apresenta uma situação melhor para a média dos municípios brasileiros, em relação à média dos municípios PELC e VS, é o Índice de Gini, ou seja, os municípios PELC e VS são mais desiguais.

Na segunda seção foi analisada a situação da política de esporte nos municípios brasileiros e nos municípios beneficiários do PELC e VS, com base nos dados da Munic 2016 para quatro eixos: órgão gestor; legislação; conselho municipal de esporte; e ações e programas de esporte. Os resultados mostram que, em média, os municípios PELC e VS possuíam uma política de esporte melhor institucionalizada, quando comparada com a média nacional: todos os municípios com convênio PELC ou VS possuíam órgão gestor tratando do esporte e apresentavam maior percentual de municípios com secretaria municipal exclusiva Além disso, 34\% dos municípios conveniados possuíam CME, contra $21 \%$ dos municípios brasileiros. E as três modalidades de programas (escolar, rendimento e lazer) foram executadas pela ampla maioria das prefeituras. A legislação é o único aspecto com números semelhantes para os dois grupos (78\% Brasil e $80 \%$ PELC e VS).

Os resultados encontrados nas duas primeiras seções apontam para o desafio de democratizar o lazer e o esporte recreativo, objetivo geral dos programas. É preciso levar os programas para todas as regiões brasileiras de maneira mais igualitária, 
incluindo mais municípios de pequeno porte, que tenham menor desempenho socioeconômico e baixo grau de institucionalização da política de esporte.

$\mathrm{Na}$ terceira seção do artigo foram apresentados e analisados os dados dos Mimboé, aqueles que melhor captam os indicadores utilizados para verificar se os objetivos dos programas foram alcançados. Cabe ressaltar que muitos dos convênios não tinham as informações para todos os instrumentos que constam no Sistema. Também não foi possível captar, por meio dos instrumentos disponíveis, alguns indicadores, por exemplo, aqueles referentes ao perfil dos beneficiários.

As informações disponíveis no Mimboé apontam um quadro bastante positivo para os programas em relação aos seus objetivos. Mas há indicadores que apontam desafios e merecem atenção pelo fato de não corresponderem, em maior ou menor grau, aos objetivos dos programas.

A conclusão geral do artigo é que os resultados foram satisfatórios para grande parte dos indicadores, mas que alguns desafios se apresentam para o aperfeiçoamento dos programas. Dentre os resultados mais positivos, cabe destacar:

- As atividades sistemáticas eram diversificadas, adequadas ao público-alvo dos programas e comtemplavam alguma ação intergeracional. Também apresentavam metodologia de planejamento participativa e dialogavam com a cultura local.

- As atividades assistemáticas eram, em sua grande maioria, planejadas de forma participativa pelos convenentes e dialogavam com a cultura local. Em geral, os convenentes costumavam executar atividades assistemáticas mensalmente.

- Os convênios contavam, amplamente, com entidades parceiras no desenvolvimento dos programas; em média, eram quatro as entidades parceiras para 
cada convênio. A maior parte das entidades eram instituições públicas e contribuíram com os programas disponibilizando infraestrutura.

- Em 90\% dos convênios com informações, gestores, agentes sociais e beneficiários contribuíram para as festividades organizadas pela comunidade local. Além disso, a entidade convenente tinha boa capacidade de organização e mobilização da comunidade. Ainda, em $62 \%$ dos convênios houve a atuação de lideranças comunitárias nos programas.

- A maioria dos convenentes criou o conselho gestor que, predominantemente, reuniu-se mensalmente (46\%) ou bimestralmente (31\%). Também essa instituição teve diversidade em sua composição.

- Todos os municípios conveniados possuíam órgão gestor tratando do esporte e lazer.

- A adesão aos programas possibilitou a ressignificação/qualificação de espaços públicos para abrigar núcleos ou subnúcleos em $62 \%$ dos convênios.

- A formação presencial de agentes sociais de esporte e lazer, realizada pela UFMG, é um dos principais eixos do programa. Foram 304 formações PELC e 112 formações VS realizadas de 2013 a 2017, o que resultou em 16.582 agentes sociais de esporte e lazer formados.

- A divulgação dos programas é ampla, em termos de recursos utilizados, inclusive a internet.

Em relação aos desafios que precisam ser trabalhados pelos programas para que esses sejam aperfeiçoados e alcancem melhores resultados, vale destacar: 
- A instabilidade em sua implementação, conforme variação no número de convênios firmados ao longo do ano, exemplar é o ano de 2016 que não teve qualquer conveniamento;

- A concentração regional dos programas no Sudeste e em municípios mais populosos e que apresentam melhores condições socioeconômicas, considerados PIB per capita e IDHM.

- A grade horária das atividades sistemáticas foi comprida na maioria dos convenentes (52\%), mas há um percentual significativo que só o fez parcialmente $(35 \%)$ ou não o fez (14\%). Ainda, tem-se um número expressivo que não as dispuseram em local visível e acessível e não a atualizaram no Mimboé.

- A entidade de controle social parece ser pouco atuante nas atividades sistemáticas e assistemáticas: $65 \%$ não acompanharam as atividades sistemáticas e $52 \%$ não acompanharam as atividades assistemáticas.

- A baixa formação de grupos de comunidade, convivência, culturais e esportivos a partir dos programas.

- As incertezas quanto à municipalização das atividades de esporte e lazer implementadas a partir do PELC e VS. Nas respostas, encontra-se $71 \%$ que buscarão estratégias para dar continuidade aos programas, o que é uma informação positiva. Contudo, perguntados sobre a estratégia para isso, 38\% apontaram que é realizar novo convênio com o ME. Ainda, 53\% defenderam que o período de vigência do convênio é insuficiente para garantir a continuidade do programa após o fim seu término.

- A formação em serviço foi realizada por $90 \%$ dos convênios pesquisados, o que é bastante positivo. Contudo, prevalecem as reuniões pedagógicas da equipe de trabalho como método de formação e baixa participação de representantes de entidades 
de controle social e de beneficiários dos programas. A utilização do EaD também é baixa e precisa ser potencializada, principalmente considerando a oferta de cursos disponibilizada nesta modalidade de ensino pela UFMG, a partir da parceria com o ME.

- Apesar do uso da internet para divulgar os programas, ela é ainda muito pouco utilizada para inscrição de participantes nas atividades sistemáticas.

- Na condição de programas sociais que buscam a inclusão de população mais carente, é também reduzida a oferta de auxílios para o deslocamento da população para as oficinas.

Os resultados apresentados neste artigo mostram a importância do monitoramento e avaliação de políticas públicas. Tem-se um conjunto amplo e robusto de informações que possibilitam tomadas de decisão e aperfeiçoamento nos programas de esporte e lazer do Ministério do Esporte. Isso aponta para o sucesso do Mimboé e cria novas demandas para o mesmo na produção e divulgação de informações sobre o PELC e o VS.

\section{REFERÊNCIAS}

BRASIL, Ministério do Esporte. Indicadores Mimboé. ME/UFMG: Belo Horizonte, 09 de setembro de 2014.

BRASIL. Ministério do Esporte. Programa Esporte e Lazer da Cidade (PELC) Diretrizes 2016. Brasília: SNELIS, 2016a. Disponível em: http://www.esporte.gov.br/arquivos/snelis/2016/Diretrizes/Diretriz_PELC_2016_atualiz ada.pdf. Acesso em: 08 ago. 2017.

BRASIL. Ministério do Esporte. Programa Vida Saudável (VS) - Diretrizes 2016. Brasília: SNELIS, 2016b. Disponível em: http://www.esporte.gov.br/arquivos/snelis/2016/Diretrizes/Diretriz_Vida_Saudvel_2016 _atualizada.pdf. Acesso em: 08 ago. 2017.

BRASIL. Ministério do Esporte. Planilha CGLIS de Convênios 2013-2015. Brasília: SNELIS - CGLIS, jan. 2018a. 
BRASIL. Ministério do Esporte. Sistema de Monitoramento e Avaliação do PELC e Vida Saudável - Mimboé. Extrator de Indicadores. Brasília: Ministério do Esporte, jan. 2018b.

IBGE, em parceria com os Órgãos Estaduais de Estatística, Secretarias Estaduais de Governo e Superintendência da Zona Franca de Manaus - SUFRAMA. Produto Interno bruto dos municípios: 2010-2014. Rio de Janeiro: IBGE, 2016.

IBGE, Diretoria de Pesquisas - DPE - Coordenação de População e Indicadores Sociais - COPIS. Estimativas da população residente no Brasil e unidades da federação com data de referência em $\mathbf{1}^{\mathbf{0}}$ de julho de 2015. Rio de Janeiro: IBGE, 2017a.

IBGE. Perfil dos municípios brasileiros: pesquisa de informações básicas municipais (Munic). Suplemento Especial de Esporte. Rio de Janeiro: IBGE, 2017 b.

PNUD. Programa das Nações Unidas para o Desenvolvimento. Atlas do desenvolvimento humano no Brasil, 2013. Disponível em: http://www.br.undp.org/content/brazil/pt/home/ . Acesso em: 09 abri. 2017.

SOARES, Márcia M.; GUADANINI, Aline. Segundo Relatório de Indicadores dos Programas Esporte e Lazer da Cidade e Vida Saudável (2013-2015). Belo Horizonte, mar. 2018.

UFMG. Escola de Educação Física, Fisioterapia e Terapia Ocupacional (EEFFTO). Planilha Formações PELC e VS. Equipe Gestora do Projeto de Formação do Programa Esporte e Lazer da Cidade (PELC), Belo Horizonte: UFMG/EEFFTO, mar. de 2018.

\section{Endereço das Autoras:}

Márcia Miranda Soares

Faculdade de Filosofia e Ciências Humanas - Fafich

Av. Pres. Antônio Carlos, 6.627 - sala 4089 - Pampulha

Belo Horizonte - MG - 31.270-901

Endereço Eletrônico: marciamsoares@uol.com.br

Aline Souza Guadanini

Rua Carlos Guadanini, 133 - Santo Antônio

Ribeirão das Neves - MG - 33.805-110

Endereço Eletrônico: alinesguadanini@gmail.com 